\title{
Differential expression of Arc in the mesocorticolimbic system is involved in drug and natural rewarding behavior in rats
}

\author{
Mu LI ${ }^{1}$, Wen-jie LIU ${ }^{1}$, Bin LU ${ }^{1}$, Yu-hua WANG ${ }^{1,2}$, Jing-gen LIU ${ }^{1, *}$ \\ ${ }^{1}$ State Key Laboratory of Drug Research, Shanghai Institute of Materia Medica, Chinese Academy of Sciences, Shanghai 201203, \\ China; ${ }^{2}$ School of Pharmacy, Nanjing University of Chinese Medicine, Nanjing 210046, China
}

\begin{abstract}
Aim: To investigate the different effects of heroin and milk in activating the corticostriatal system that plays a critical role in reward reinforcement learning.

Methods: Male SD rats were trained daily for $15 \mathrm{~d}$ to self-administer heroin or milk tablets in a classic runway drug self-administration model. Immunohistochemical assay was used to quantify Arc protein expression in the medial prefrontal cortex (mPFC), the nucleus accumbens (NAc), the dorsomedial striatum (DMS) and the ventrolateral striatum (VLS) in response to chronic self-administration of heroin or milk tablets. NMDA receptor antagonist MK801 (0.1 mg/kg) or dopamine D1 receptor antagonist SCH23390 (0.03 mg/kg) were intravenously injected at the same time as heroin was infused intravenously.

Results: Runway training with heroin resulted in robust enhancement of Arc expression in the mPFC, the NAc and the DMS on d 1, 7, and 15, and in the VLS on $\mathrm{d} 1$ and $\mathrm{d}$ 7. However, runway training with milk led to increased Arc expression in the mPFC, the NAc and the DMS only on d 7 and/or d 15 but not on d 1 . Moreover, runway training with milk failed to induce increased Arc protein in the VLS. Both heroin-seeking behavior and Arc protein expression were blocked by MK801 or SCH23390 administration.

Conclusion: The VLS is likely to be critically involved in drug-seeking behavior. The NMDA- and D1 receptor-dependent Arc expression is important in drug-seeking behavior.
\end{abstract}

Keywords: addiction; drug reinforcement; the runway model; Arc/Arg3.1; medial prefrontal cortex; striatum; heroin; MK801; SCH23390

Acta Pharmacologica Sinica (2013) 34: 1013-1024; doi: 10.1038/aps.2013.28; published online 27 May 2013

\section{Introduction}

The mesocorticolimbic system plays important roles in reward, motivation, learning and addiction. The striatum and the medial prefrontal cortex (mPFC) are critical components of the mesocorticolimbic network. The striatum is thought to be critical for learning functions, especially reinforcementbased learning ${ }^{[1,2]}$. The dorsomedial striatum (DMS), which receives input primarily from the prefrontal cortex ${ }^{[3]}$, appears to be preferentially involved in the rapid acquisition of actionoutcome behavior $^{[4,5]}$ and is thought to contribute to the early performance of drug-seeking behavior. By contrast, the lateral striatum, which receives input from the sensorimotor cortex ${ }^{[3]}$, is critical for the acquisition of stimulus-response habitual behavior $^{[4,6]}$ and is thought to be involved in cue-controlled forms of addictive behavior after extensive drug-taking experience ${ }^{[7,8]}$. The lateral striatum is also involved in the rein-

\footnotetext{
* To whom correspondence should be addressed.

E-mail jgliu@mail.shcnc.ac.cn

Received 2013-02-20 Accepted 2013-03-06
}

statement of drug seeking after protracted withdrawal and in relapse to a drug-seeking state ${ }^{[9,10]}$. The nucleus accumbens (NAc) has a key role in drug self-administration by mediating Pavlovian influences on instrumental seeking behavior ${ }^{[11,12]}$, as well as mediating the reinforcing effects of stimulant drugs $^{[13]}$. The mPFC can exert a strong influence on the performance of instrumental actions. Lesions of the $\mathrm{mPFC}$ result in behavior that is insensitive to changes in outcome value in animals and in compulsive behavior in several human psychopathologies ${ }^{[14,15]}$. Although addictive drugs and natural rewards both activate mesocorticolimbic reward reinforcing systems, only addictive drugs induce compulsive use. The differences in the activation of the striatum and the mPFC by the drug and by natural rewards are unclear.

The expression of specific immediate-early genes (IEGs) is induced by neural activity that produces stable changes in synaptic plasticity ${ }^{[16,17]}$ and by behavioral training ${ }^{[18,19]}$. Activity-regulated cytoskeletal-associated gene (Arc) is robustly induced by plasticity-producing stimulation and by various forms of behavioral learning ${ }^{[20]}$, and it is necessary for the 
stabilization of that synaptic plasticity and for some forms of long-term memory ${ }^{[21,22]}$. Because Arc shows the peculiar feature of being delivered into dendrites and because it is localized selectively at active synapses ${ }^{[23]}$, it has been proposed as a marker of synaptic plasticity for mapping the brain sites involved in learning and memory. To investigate the different effects of addictive drugs and natural rewards on the mesocorticolimbic system, we compared the expression of Arc protein in the $\mathrm{mPFC}$, the NAc core, and different parts of the striatum in response to chronic self-administration of heroin or milk tablets using a classic runway drug self-administration paradigm $^{[24,25]}$.

\section{Materials and methods Materials}

Heroin (diacetylmorphine hydrochloride) was obtained from the National Institute of Forensic Science (Beijing, China). MK801 (0.1 mg/kg) and SCH23390 (0.03 mg/kg) were purchased from Sigma (St Louis, MO, USA). Anti-Arc antibody (mouse, 1:200 dilution) was purchased from Santa Cruz Biotechnology (Santa Cruz, CA, USA). Biotin-goat anti-mouse $\operatorname{IgG}(1: 200)$, the SABC kit and the DAB kit were obtained from Wuhan Boster Biological Technology (Wuhan, China).

\section{Animals}

The subjects were male Sprague Dawley rats obtained from the Laboratory Animal Center, Chinese Academy of Sciences (Shanghai, China), weighing between 280 and $300 \mathrm{~g}$ at the beginning of each experiment. All animals were housed in groups in a temperature-controlled room $\left(24 \pm 2^{\circ} \mathrm{C}\right)$ on a $12 \mathrm{~h}$ light/12 h dark cycle (lights on at 7:00 AM). Rats were allowed ad libitum access to food and water in their home cages throughout the experiments. All animal use protocols were reviewed and approved by the Institutional Animal Care and Use Committee (IACUC) of Shanghai Institute of Materia Medica (SIMM), which received the full accreditation of AAALAC in May 2011. All procedures were executed in accordance with the IACUC guidelines and polices. A total of 181 rats were used in the experiments described below.

\section{Intravenous catheterization surgery}

Rats (weighing 280-300 g when surgery began) were anesthetized with sodium pentobarbital (55 mg/ $\mathrm{kg}$, ip) in combination with atropine $(0.4 \mathrm{mg} / \mathrm{kg}$, ip). The catheters, which were constructed using guide cannulae, silicon tubing, dental cement and plugs, were implanted with the proximal end reaching the atrium through the right jugular vein, continuing dorsally over the right shoulder and fixed between the scapulae $^{[26]}$. The catheters were flushed daily with $0.2 \mathrm{~mL}$ of an antibiotic solution (penicillin sodium dissolved in $2 \mathrm{~mL}$ $0.9 \%$ sterile saline) and thereafter daily with $0.1 \mathrm{~mL}$ heparin solution (50 units $/ \mathrm{mL}$ in $0.9 \%$ sterile saline). The rats were allowed to recover from surgery for $3-5 \mathrm{~d}$.

\section{Runway experiments}

The runway apparatus was a straight polyvinyl chloride
(PVC) alley (Figure 1A) ${ }^{[23]}$. The runway apparatus was a slight modification of the runway designed by Ettenberg and coworkers $^{[24]}$. The modified runway apparatus was $200 \mathrm{~cm}$ long, $10 \mathrm{~cm}$ wide and $45 \mathrm{~cm}$ high, and it included a start area, a goal area (length, $30 \mathrm{~cm}$ each), a straight alley, a magnet track, a flow-through swivel and a drug delivery system. The start area was separated from the alley by a sliding door. The goal area had black walls with white stripes, serving as the visual discriminative stimulus; in addition, a tone generator located in the ceiling of the goal area was available to provide an auditory discriminative stimulus. The floor of the runway was made with steel grids. The subject's activity within the apparatus was detected by breaking two transverse infrared photodetectors, which were embedded in the wall between the start area and goal area. A computer program for the control of operant behavioral experimentation from Anilab Software and Instrument Co, Ltd (China) was used. The heroin was dissolved freshly in sterile $0.9 \%$ physiological saline at a concentration of $120 \mu \mathrm{g} / \mathrm{kg}$. Drug or vehicle solution was intravenously delivered at a speed of $20 \mu \mathrm{L}$ per second.

Before measuring heroin-induced drug-seeking behavior, rats were taken out of their home cages once daily and handled for at least $5 \mathrm{~min}$ per rat for at least $5 \mathrm{~d}$. After handling and habituation, and at least $3 \mathrm{~d}$ of recovery from surgery, 24 of the 181 rats were divided into two equal groups (the saline group and the heroin group) to test for the runway behavior. Each rat was trained daily for 15 consecutive days (one trial per day), and rats were trained to run to the goal area for selfadministration of heroin $(120 \mu \mathrm{g} / \mathrm{kg}$ per infusion, iv) or saline. A rat was put into the start area for approximately $5 \mathrm{~s}$. Then, the door was opened, and the animal was free to traverse the alley. The runway apparatus was high, so the rat had no visual contact with the experimenter, who stood apart. When the rat broke the photobeam and reached the goal area, it was led to an intravenous injection of heroin or saline accompanied by four distinctly audible clicks and the illumination of the goal area light. The rat was allowed to stay in the runway apparatus for approximately 6 min before it was returned to its home cage. If the animal did not traverse the $200-\mathrm{cm}$ alley within $60 \mathrm{~s}$, it was gently shoved through the runway to the goal area. The "run time" was defined as the timespan when the rat ran out of the start area, travelled through the alley and finally entered the goal area. The "latency" was defined as the time until the rat left the start area.

To measure food-rewarded activities, rats were placed on a restricted diet two weeks before the runway training, receiving 10-15 g of their maintenance diet daily to reach $80 \%-85 \%$ of free feeding weight throughout the experiments ${ }^{[5]}$. Once the training began, rats were fed each day after the training sessions, and they had free access to water while in their home cages. Eighteen of the 181 rats were divided equally into two groups (a water group and a milk tablets group). When a milk-group rat ran into the goal area and broke the photobeam, the experimenter gave the rat four milk tablets through a tube on the wall of the goal area from outside the runway apparatus, and the milk tablets dropped into the goal area 
along the tube. The water-group rats, similarly, found water in the goal area. The effective response was also accompanied with the light/tone cues: four distinctively audible clicks and the illumination of the goal area light. The rat was allowed to stay in the runway apparatus and consume the milk tablets for approximately $6 \mathrm{~min}$ before it was returned to its home cage. Two hours after the training, free access to the restricted food was available.

To measure the effect of heroin treatment on Arc expression in the absence of runway training, forty-eight of the 181 rats were used. They were divided into six groups: withoutrunway saline groups and without-runway heroin groups at three different time points per treatment $(1,7$, and $15 \mathrm{~d}, n=8$ per group). After recovery from the intravenous catheterization surgery, these rats were intravenously injected with saline or heroin $(120 \mu \mathrm{g} / \mathrm{kg})$ at their home cages. On the final day of the injection, rats were quickly anesthetized and perfused according to the immunohistochemistry protocol below.

For the antagonist tests, thirty-five of the 181 rats were used. They were divided into four groups: the saline group, $n=6$; the heroin group, $n=11$; the MK801 group, $n=10$; and the SCH23390 group, $n=8$. MK801: $0.1 \mathrm{mg} / \mathrm{kg}^{[27]}$. SCH23390: 0.03 $\mathrm{mg} / \mathrm{kg}^{[28]}$. To avoid changes in locomotor activity induced by MK801 or SCH23390, these two antagonists were administered (iv) when rats ran through the alley and broke the photobeam in the goal area to ensure that the antagonists were administered at the same time as heroin was infused intravenously. The Arc protein expression levels in the antagonist tests were assayed in the rats used in the behavioral tasks.

\section{Immunohistochemistry}

Brain sections from different groups were processed in parallel to minimize the variations in immunohistochemical labeling. To further determine the temporal pattern of Arc protein expression, we analyzed three different time points $(1,7$, and $15 \mathrm{~d}$ ) of heroin- or food-rewarded runway training. For this purpose, we used thirty-six of the 181 rats and divided them into six groups ( $n=6$ per group, saline group and heroin group at three different time points). For food-reward analysis, we used forty-eight of the 181 rats and divided them into six groups ( $n=8$ per group, water group and milk tablets group at three different time points). For the $\mathrm{d} 15$ time point of heroin or milk tablet runway training, Arc protein expression levels were assayed in the rats used in the behavioral tasks. For antagonist treatment, we used twenty-four of the 181 rats, divided into four groups ( $n=6$ per group), and Arc protein expression was assayed in the rats used in the behavioral tasks.

After the last day of the training, rats were removed from the runway apparatus, and one hour later, they were quickly anesthetized with sodium pentobarbital (55 mg/kg, iv). For light microscopy, deeply anesthetized rats were perfused with saline and then $4 \%$ cold paraformaldehyde in $0.1 \mathrm{~mol} / \mathrm{L}$ phosphate buffer. Brains were removed from the skulls and postfixed in $4 \%$ paraformaldehyde overnight at $4{ }^{\circ} \mathrm{C}$. The next day, the brains were transferred to a solution of $30 \%$ sucrose overnight until they sank. Cryostat sections of these brains were then cut at a thickness of $30 \mu \mathrm{m}$ on a Leica CM3050S cryostat. Brain sections were stored in 10\% sucrose and $0.03 \%$ sodium azide in $0.1 \mathrm{~mol} / \mathrm{L}$ phosphate buffer at $4{ }^{\circ} \mathrm{C}$ for further processing ${ }^{[29]}$. Standard immunocytochemical methods were performed as previously described in detail ${ }^{[30]}$. All washes were conducted in $0.1 \mathrm{~mol} / \mathrm{L}$ phosphate buffer, and sections were blocked with $10 \%$ normal goat serum for $2 \mathrm{~h}$ at room temperature. Sections were incubated overnight in primary antibody (mouse anti-Arc antibody, 1:500 dilution in 10\% normal goat serum) at $4^{\circ} \mathrm{C}$. Then, sections were incubated with secondary antibody (biotin-goat anti-mouse IgG, 1:200 dilution in $10 \%$ normal goat serum) for $2 \mathrm{~h}$ at room temperature. Arc-positive sites were visualized using a SABC kit and a DAB kit employing $0.1 \%$ 3,3'-diaminobenzidine as the chromogen. The brain sections were subsequently dehydrated in alcohol and xylene and coverslipped. Finally, they were imaged on an Olympus IX51 microscope.

To quantitatively examine the protein expression data, fields measuring 200× magnification in the brain slices were digitally captured, and the integrated optical density (IOD) of positive cells was automatically counted using Image Pro Plus software.

\section{Statistical analysis}

Data are presented as the mean \pm SEM. Data were analyzed with ANOVAs using the appropriate between- and withinsubject factors for different experiments (see Results). Significant main effects and interactions $(P<0.05)$ from the factorial ANOVAs were followed by simple ANOVAs and Bonferroni post hoc tests. Additionally, for clarity, post hoc analyses are indicated in the figures but are not described in the Results.

\section{Results}

\section{Runway training with heroin and milk both induced motivational} behavior

We detected the mean run time and the latency in four different groups of rats that underwent runway training with heroin or milk over the course of $15 \mathrm{~d}$. The incentive motivational effects of heroin were progressively reinforced after $15 \mathrm{~d}$ of the training ( $n=12$ in each group) and manifested in a progressive increase in runway speed (Figure 1B). Analysis of the run time (time to enter the goal area once the rat had left the start area) and the latency (time to leave the start area) using ANOVA with between-subject factors of heroin and training days revealed a significant effect of heroin $\left(F_{(1,308)}=13.44, P<0.01\right)$ and training days $\left(F_{(14,308)}=5.63, P<0.01\right)$ and a significant interaction between these two factors $\left(F_{(14,308)}=7.63, P<0.01\right)$. The analysis of the latency revealed no significant effect of heroin $\left(F_{(1,308)}=2.05, P>0.05\right)$ or training days $\left(F_{(14,308)}=2.45, P>0.05\right)$ and an interaction between these two factors $\left(F_{(14,308)}=3.09, P>0.05\right)$. Post hoc Bonferroni differences within each time point are indicated in Figure 1B. Rats that underwent runway training with heroin for 15 consecutive days ran much faster than those trained with saline for $15 \mathrm{~d}$; however, the two groups spent similar amounts of time in the start area. 

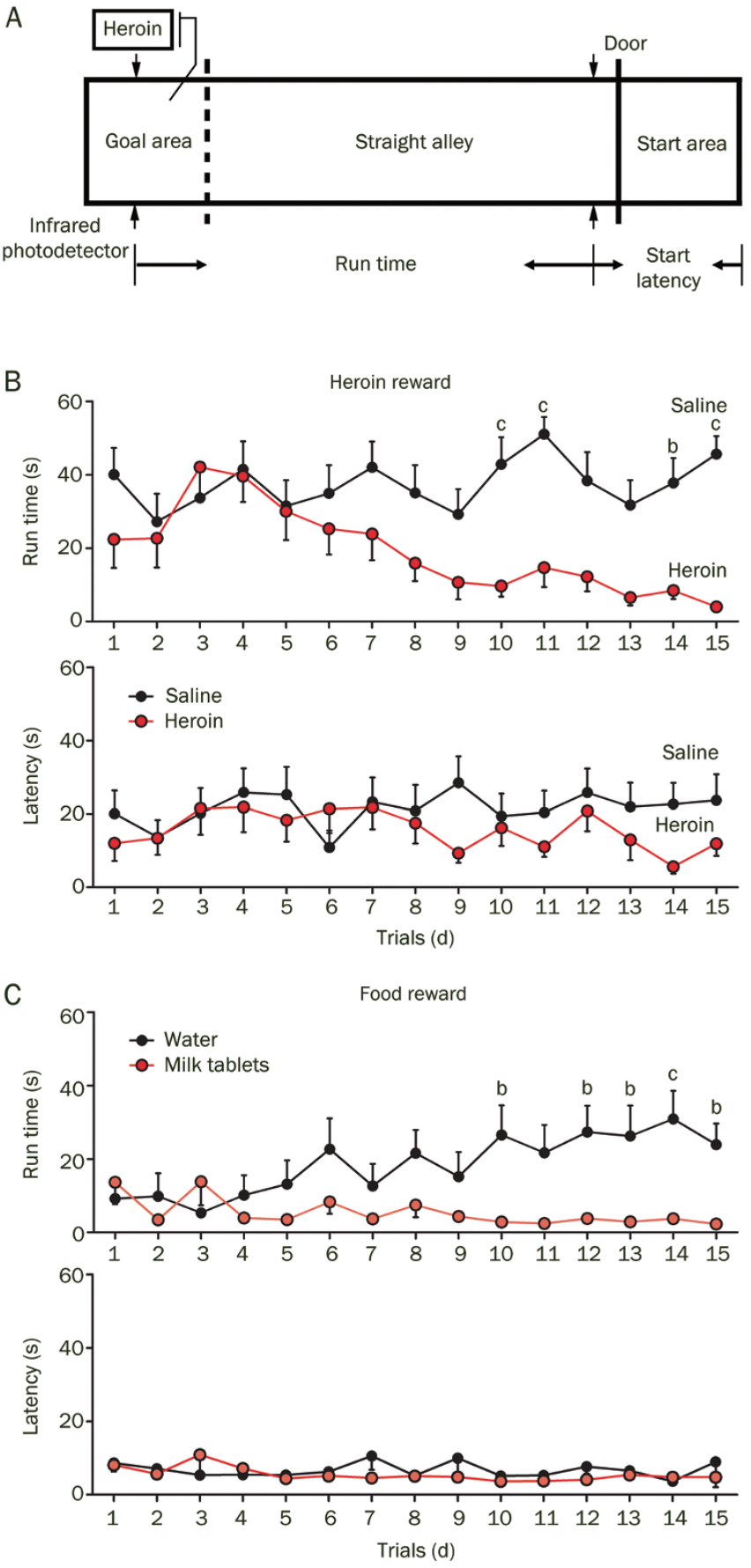

Figure 1. (A) Schematic of the runway drug self-administration model. (B) Development of drug reinforcement in a runway procedure. Rats were given the opportunity to run for an intravenous injection of saline $(n=12)$ or $120 \mu \mathrm{g} / \mathrm{kg}$ heroin $(n=12)$ in 15 consecutive trials (days). The figures show the effects on the run time and the latency. The run time of every trial reflected the incentive (heroin) delivered upon goal-area entry and provided an index of the animal's motivation to seek the reinforcer in the trial. (C) Development of food reinforcement in a runway procedure. Food-restricted rats were given the opportunity to run for milk tablets $(n=9)$ versus water $(n=9)$ in 15 consecutive trials. Data are expressed as the mean \pm SEM. ${ }^{b} P<0.05,{ }^{c} P<0.01$ with respect to the heroin group or the milk tablets group by two-way ANOVA followed by the Bonferroni post hoc tests.
The incentive motivational effects of milk were also reinforced after $15 \mathrm{~d}$ of the training ( $n=9$ in each group, Figure $1 \mathrm{C}$ ). Analysis of the mean run time of the milk group with ANOVA using the between-subjects factors of milk tablets and training days revealed a significant effect of milk tablets $\left(F_{(1,224)}=15.46\right.$, $P<0.01)$, but no significant effect of training days $\left(F_{(14,224)}=4.03\right.$, $P>0.05)$, and a significant interaction between these two factors $\left(F_{(14,224)}=9.25, P<0.01\right)$. The analysis of the latency revealed no significant effect of milk $\left(F_{(1,224)}=0.94, P>0.05\right)$ or training days $\left(F_{(14,224)}=4.06, P>0.05\right)$ and an interaction between these two factors $\left(F_{(14,224)}=4.56, P>0.05\right)$. Post hoc Bonferroni differences within each time point are indicated in Figure 1C. Rats that underwent runway training with milk for $15 \mathrm{~d}$ ran much faster to the goal area than those trained with water for $15 \mathrm{~d}$; however, the two groups displayed similar times before leaving the start area.

Increase in Arc protein expression in the mPFC and the NAc in response to runway training with heroin in rats

Arc is a marker of synaptic plasticity and is commonly used to map the neural circuits that are involved in learning and memory. To examine the neural substrates that are recruited by runway training with heroin, we used immunohistochemistry as an approach to map Arc protein expression in the mPFC, the NAc and the striatum on $\mathrm{d} 1,7$, and 15 with or without runway training (with runway: $n=6$ per group; without runway: $n=8$ per group). As shown in Figure 2, runway training with heroin induced a marked enhancement of Arc protein expression in the mPFC (Figure 2A) and the NAc (Figure 2B) compared to runway training with saline. Two-way ANOVA

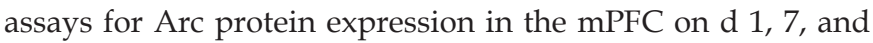
15 with or without runway training revealed a significant effect of heroin $\left(F_{(3,48)}=69.41, P<0.0001\right)$ and training days $\left(F_{(2,48)}\right.$ $=3.96, P<0.01)$ but no significant interactions between these two factors $\left(F_{(6,48)}=1.61, P>0.05\right)$. Two-way ANOVA assays for Arc protein expression in the NAc on $\mathrm{d} 1,7$, and 15 with or without runway training also revealed a significant effect of heroin $\left(F_{(3,48)}=53.32, P<0.0001\right)$ but no significant effect of training days $\left(F_{(2,48)}=2.25, P>0.05\right)$ and no significant interactions between these two factors $\left(F_{(6,48)}=2.3, P>0.05\right)$. Post hoc group differences within each time point are indicated in Figure 2C and 2D. Runway training with heroin significantly increased Arc protein expression in both the $\mathrm{mPFC}$ and the NAc on $\mathrm{d} 1$ $(P<0.01, P<0.001)$, d $7(P<0.01)$ and d $15(P<0.01)$. To address whether that increase in Arc expression by runway training with heroin was due to the behavioral training or to the pharmacological effect of heroin, we next examined the effect of heroin without runway training on Arc expression within the mPFC and the NAc. As shown in Figures 2C and 2D, heroin treatment alone also induced robust increases in Arc expression in the mPFC and the NAc, but the magnitude of Arc expression is significantly less than that induced by heroin treatment with runway training (in the mPFC: $P<0.001$ for $\mathrm{d} 1 ; P<0.05$ for $\mathrm{d} 7 ; P<0.01$ for $\mathrm{d} 15$, in the NAc: $P<0.05$ for $\mathrm{d} 7$; $P<0.01$ for $\mathrm{d} 15$, respectively). 
A

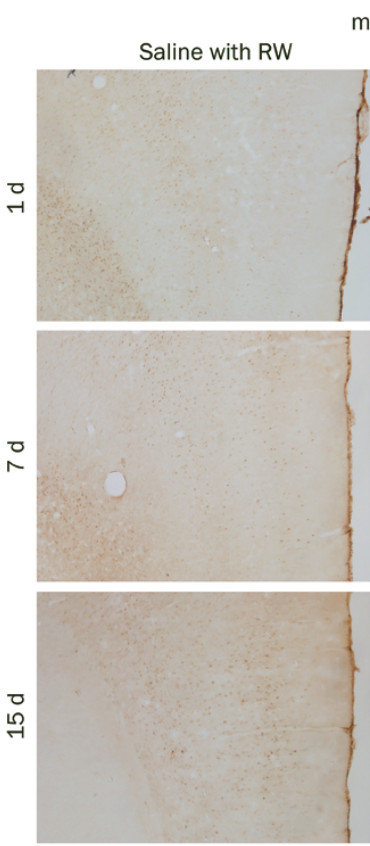

mPFC

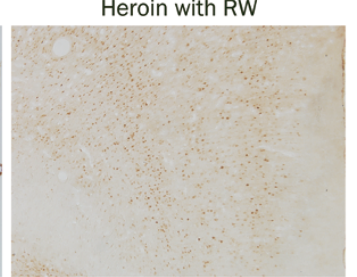

C

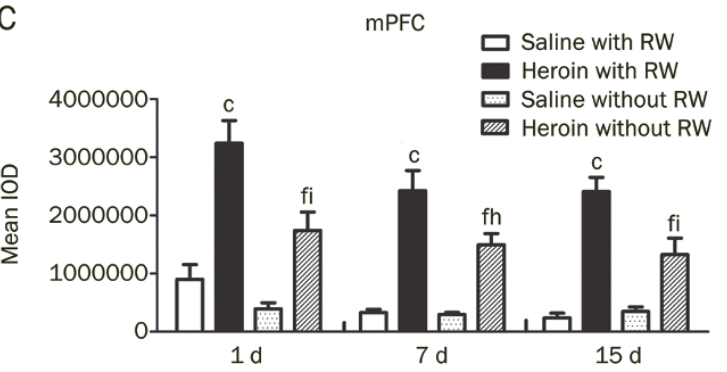

B

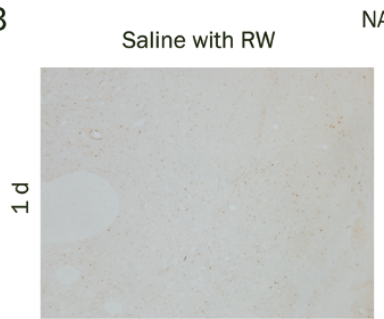

$\mathrm{NAc}$

Heroin with RW
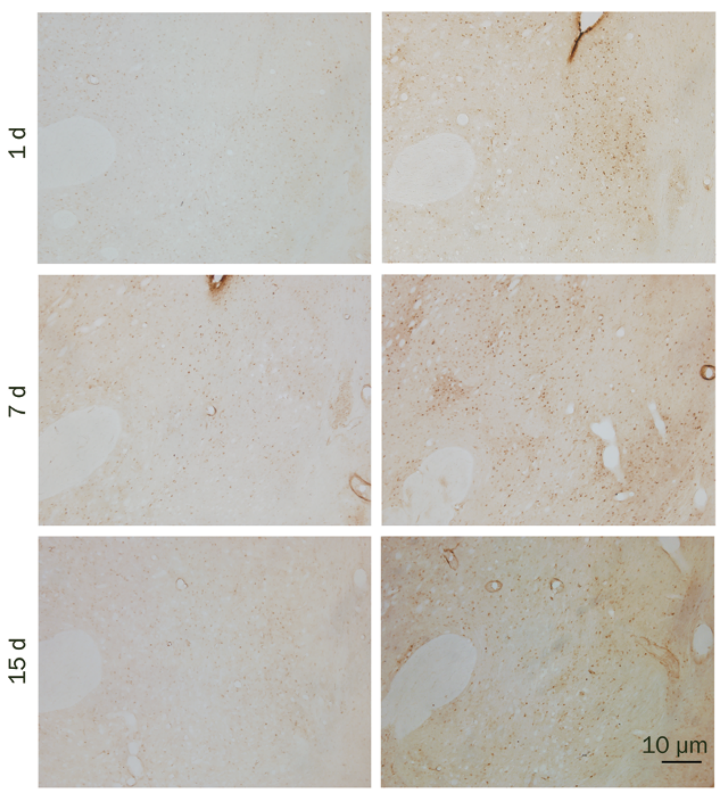

D

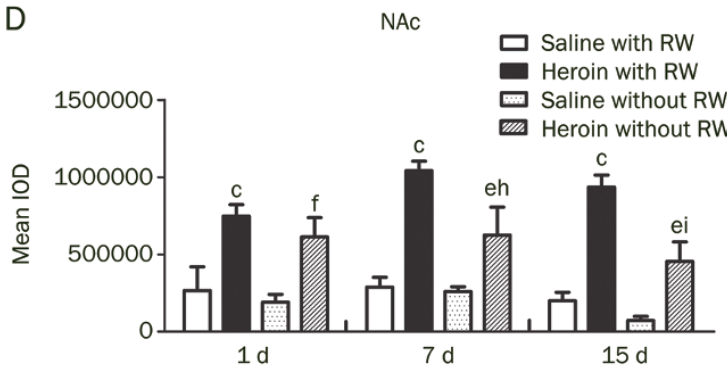

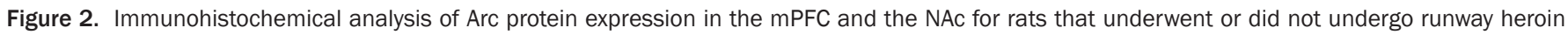

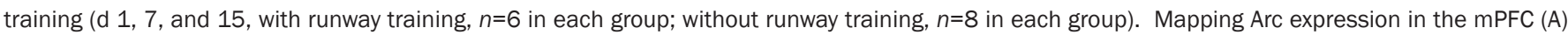

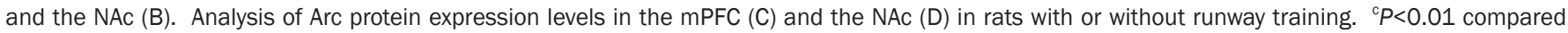

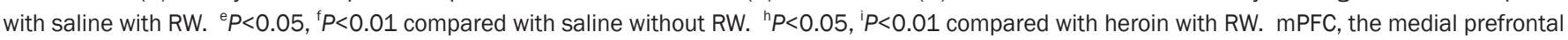
cortex; NAc, the nucleus accumbens; RW, runway. Scale bars: $10 \mu \mathrm{m}$.

Different temporal patterns of Arc protein expression in the dorsal striatum in response to runway training with heroin

Based on differences in their neuroanatomical projections, the striatum can be divided into two sub-regions: the medial striatum (MS) and the lateral striatum (LS) ${ }^{[31,32]}$. To investigate the sub-regional differences in Arc protein expression, we detected and quantified Arc protein in both the MS and the LS. As shown in Figure 3, heroin with or without runway training resulted in a robust increase in Arc protein expression on $\mathrm{d} 1$ and $\mathrm{d} 7$ in both the MS and the LS of rats, especially in the dorsomedial striatum (DMS) and the ventrolateral striatum (VLS) (Figure 3B and 3C) compared with saline (Figure 3A). However, on d 15, an increase in Arc protein expression with runway training was detected only in the DMS but not in the VLS (Figure 3D, 3E and 3F). In contrast, Arc expression was increased in the VLS by heroin on $\mathrm{d} 15$ without runway training (Figure 3F). Two-way ANOVA assays for Arc protein expression on $\mathrm{d} 1,7$, and 15 in the DMS of rats with or without runway training revealed a significant effect of heroin treatment $\left(F_{(3,48)}=41.90, P<0.0001\right)$, significant effect of training days $\left(F_{(2,48)}=5.84, P<0.01\right)$ and significant interaction between these two factors $\left(F_{(6,48)}=8.44, P<0.05\right)$. Two-way ANOVA assays for Arc protein expression in the VLS on d 1, 7, and 15 with or without runway training also revealed a significant effect of heroin $\left(F_{(3,48)}=61.12, P<0.0001\right)$ and training days $\left(F_{(2,48)}=8.30\right.$, $P<0.0001)$, as well as a significant interaction between these two factors $\left(F_{(6,48)}=19.07, P<0.0001\right)$. Post hoc group differences within each time point are indicated in Figure $3 \mathrm{E}$ and $3 \mathrm{~F}$. Runway training with heroin significantly increased Arc protein expression in the DMS on $\mathrm{d} 1(P<0.001), \mathrm{d} 7(P<0.05)$, and d $15(P<0.05)$, whereas runway training with heroin induced a significant increase in Arc protein expression in the VLS on d $1(P<0.001)$ and d $7(P<0.001)$ but not on $d 15(P>0.05)$. The results indicate that, although runway training with heroin increases Arc protein expression in both the DMS and the VLS, there was a difference in the temporal expression pattern. 
A

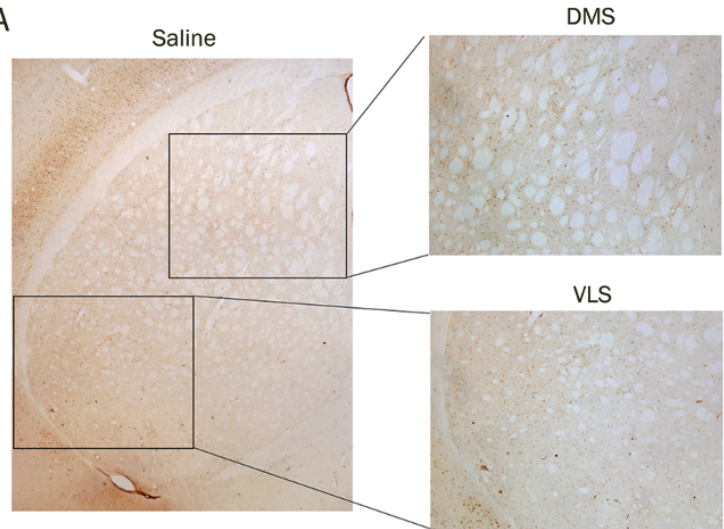

C

$7 \mathrm{~d}$ Heroin training

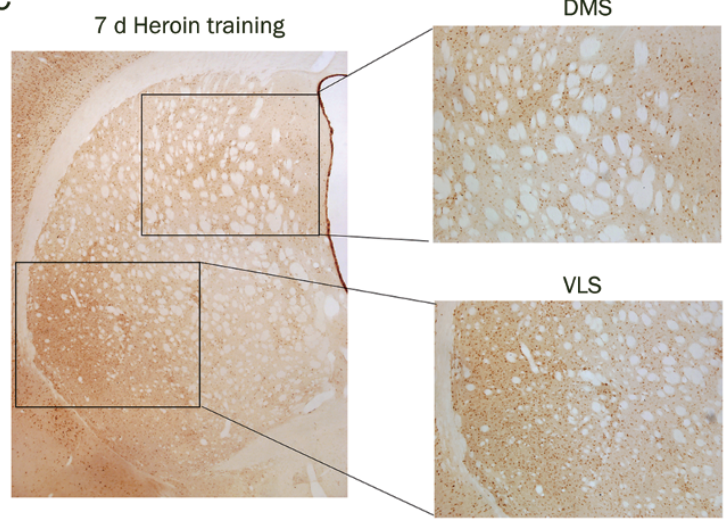

E

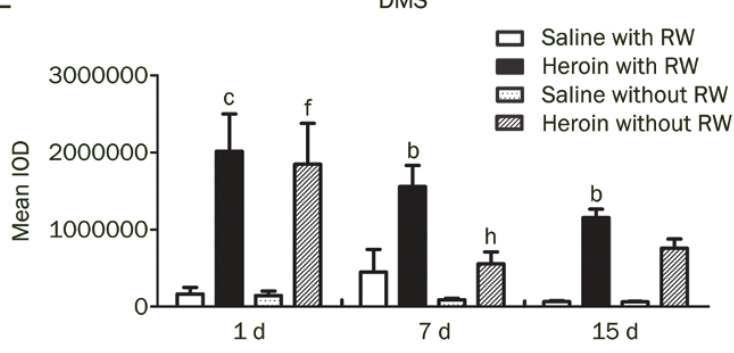

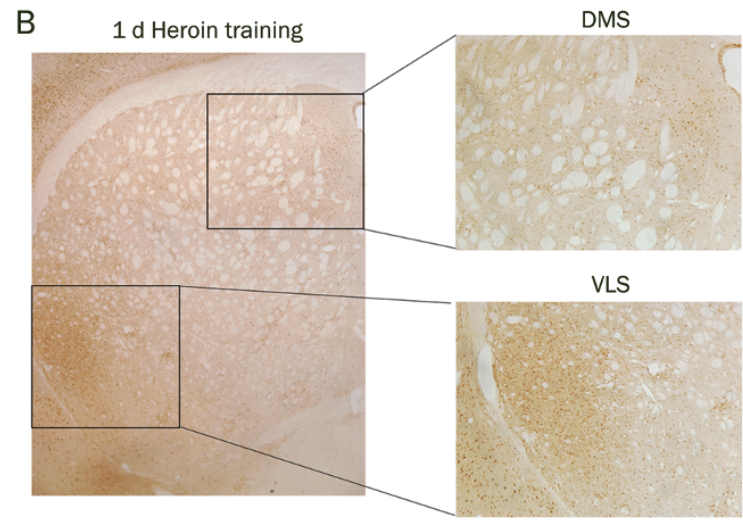

D

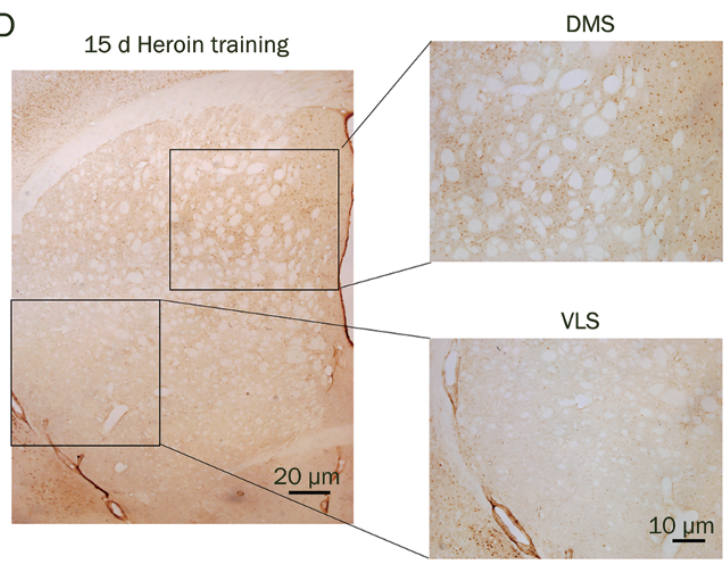

$\mathrm{F}$

VLS

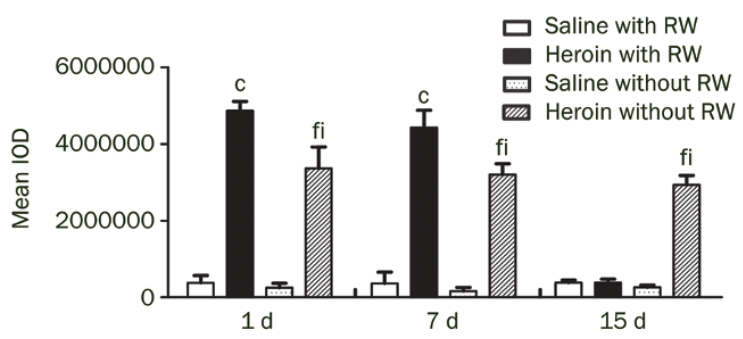

Figure 3. Immunohistochemical analysis of Arc protein expression in different regions of the striatum in rats with or without runway heroin training (d 1,7 , and 15, with runway training, $n=6$ in each group; without runway training, $n=8$ in each group). (A) Little Arc protein expression was detected in the medial and the lateral part of the striatum in salinetrained rats. (B) Increased amounts of Arc protein were found in both the DMS and the VLS in the heroin-rewarded rats on $\mathrm{d} 1$ of training. (C) Increased Arc protein levels were also found in the DMS and the VLS in the heroin rewarded rats on $\mathrm{d} 7$ of training. (D) However, unlike the DMS with persistent Arc protein expression, there was little Arc protein found in the VLS on $\mathrm{d} 15$ of heroin training. Analysis of the Arc protein expression levels in the DMS (E) and the VLS (F) in rats with or without runway training. ${ }^{\mathrm{b}} P<0.05$, ${ }^{\mathrm{c}} P<0.01$ compared with saline with RW. ${ }^{f} P<0.01$ compared with saline without RW. ${ }^{\mathrm{h}} P<0.05$, ${ }^{\mathrm{i}} P<0.01$ compared with heroin with RW. DMS, the dorsomedial striatum; VLS, the ventrolateral striatum; RW, runway. Scale bars: left image, $20 \mu \mathrm{m}$; right image, $10 \mu \mathrm{m}$.

Next, we tested the effect of heroin without runway training on Arc expression within the DMS and the VLS. As shown in Figures $3 \mathrm{E}$ and $3 \mathrm{~F}$, heroin treatment alone also induced robust increases in Arc expression in the DMS and the VLS on d 1 and $\mathrm{d}$ 7, but the magnitude of this Arc expression is significantly less than that induced by heroin treatment with runway training (in the DMS: $P<0.05$ for $\mathrm{d} 7$, in the VLS: $P<0.01$ for $\mathrm{d}$ 1; $P<0.01$ for $\mathrm{d} 7$, respectively). Interestingly, in contrast to heroin treatment with runway training, heroin treatment alone also induced a robust increase in Arc expression in the VLS on d 15 (Figure 3F).

Runway training with milk resulted in significant increases in Arc protein expression only in the MPFC, the NAc and the DMS but not in the VLS

To determine whether the same neural substrates are recruited by heroin- and milk-reward learning, we next mapped and quantified the Arc protein in the MPFC, the NAc, the DMS 
and the VLS in response to runway training with milk for 1 , 7, and $15 \mathrm{~d}$. As shown in Figure 4, runway training with milk induced enhancement of Arc protein expression in the $\mathrm{mPFC}$ and the NAc (Figure 4A and 4B). Two-way ANOVA assays for Arc protein expression in the $\mathrm{mPFC}$ on $\mathrm{d} 1,7$, and 15 revealed a significant effect of milk tablets $\left(F_{(1,28)}=31.5, P<0.01\right)$ and training days $\left(F_{(2,28)}=21.58, P<0.01\right)$, as well as a significant interaction between these two factors $\left(F_{(2,28)}=7.63, P<0.01\right)$. The following post hoc test showed that there were significant differences in Arc protein expression between runway training with milk and with water on $\mathrm{d} 7$ and d $15(P<0.01, P<0.01)$. Two-way ANOVA assays for Arc protein expression in the NAc on d 1, 7, and 15 of the training also revealed a significant effect of milk tablets $\left(F_{(1,28)}=32.32, P<0.01\right)$ and training days $\left(F_{(2,28)}=34.65, P<0.01\right)$, as well as a significant interaction between these two factors $\left(F_{(2,28)}=17.06, P<0.01\right)$. The following post hoc test showed that there were significant differences in Arc protein expression between runway training with milk and with water on $\mathrm{d} 7$ and d $15(P<0.01, P<0.01)$.

Runway training with milk also induced enhancement of Arc protein expression in the DMS but failed to induce a sig- nificant increase in Arc protein expression in the VLS (Figure 5). Two-way ANOVA assays for Arc protein expression in the DMS on $\mathrm{d} 1,7$, and 15 of runway training with milk revealed a significant effect of milk tablets $\left(F_{(1,28)}=43.97, P<0.01\right)$ and training days $\left(F_{(2,28)}=18.38, P<0.01\right)$, as well as a significant interaction between these two factors $\left(F_{(2,28)}=10.65, P<0.01\right)$. The following post hoc test showed that there were significant differences in Arc protein expression between runway training with milk and with water on $\mathrm{d} 7$ and $\mathrm{d} 15(P<0.01)$. Twoway ANOVA assays for Arc protein expression in the VLS on d 1, 7, and 15 of the training revealed no significant effect of milk tablets $\left(F_{(1,28)}=0.45, P>0.05\right)$, a significant effect of training days $\left(F_{(2,28)}=18.66, P<0.05\right)$, and no significant interactions between these two factors $\left(F_{(2,28)}=4.89, P>0.05\right)$. The following post hoc test showed that there was no significant difference in Arc protein expression between runway training with milk and with water for all time points in the VLS. These results indicate that there are temporal and spatial differences in the induction of Arc protein expression between runway training with heroin and with milk. For the rats trained with milk, significant Arc protein was observed in the mPFC, the NAc and
A
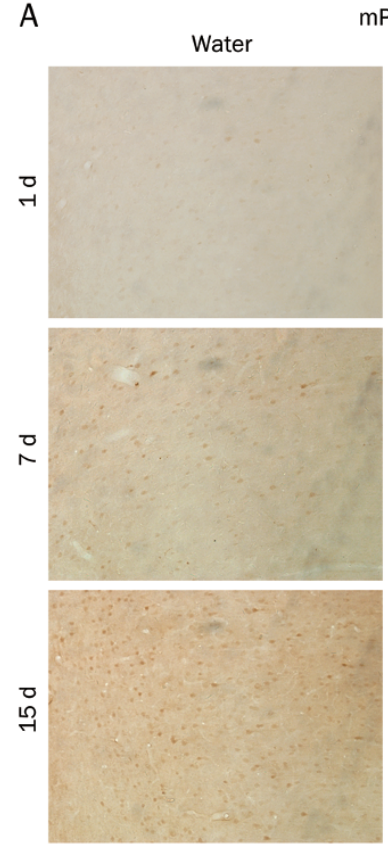

PFC
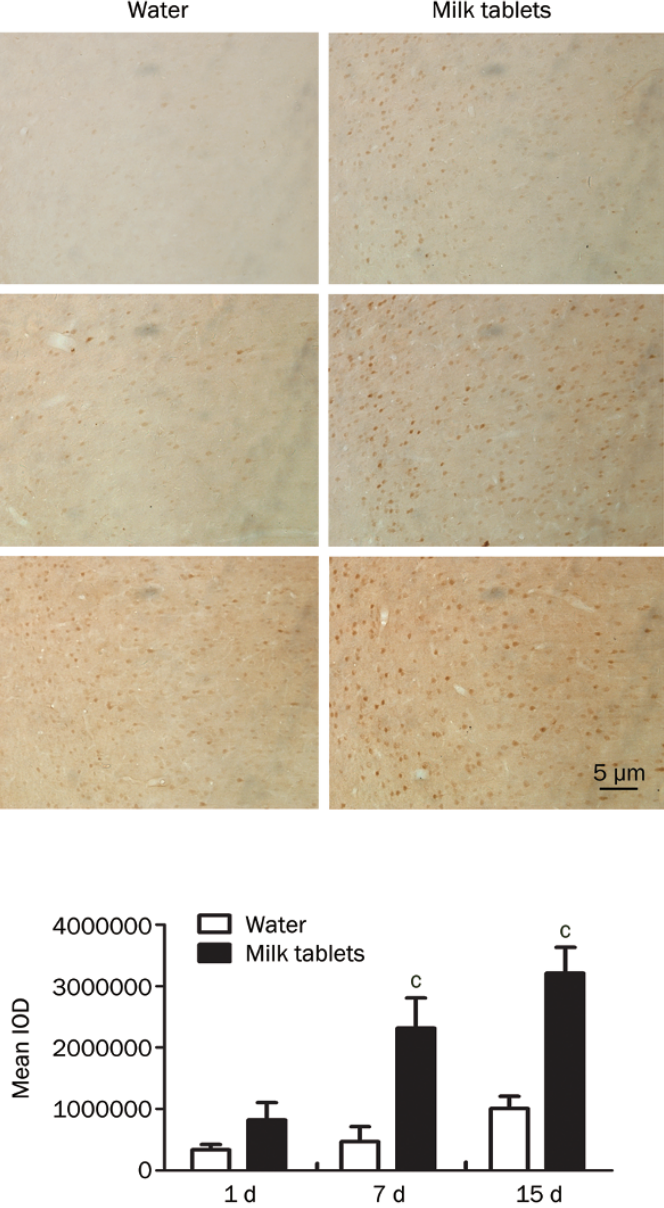

B

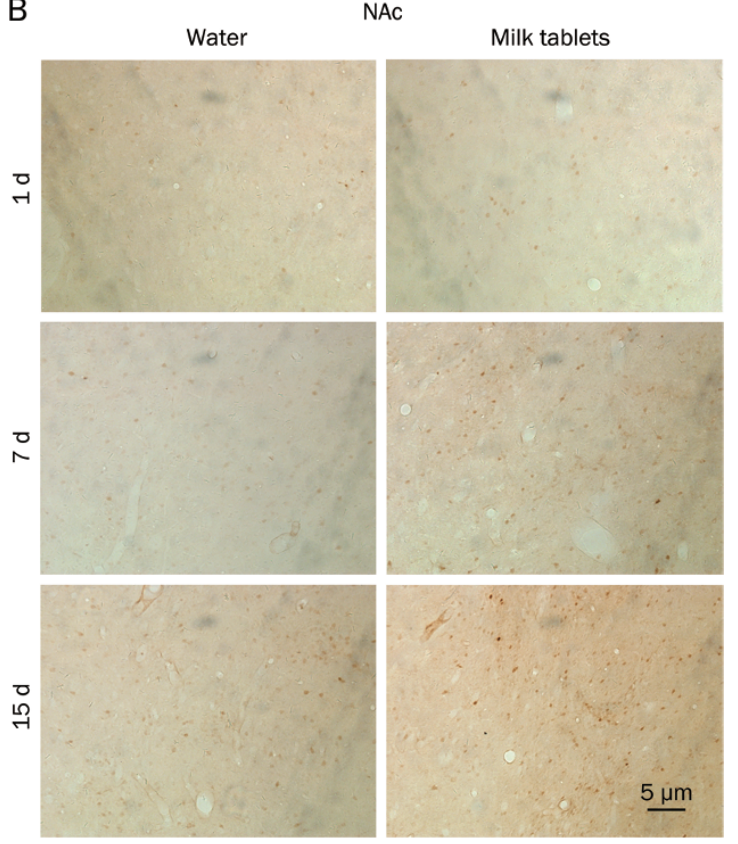

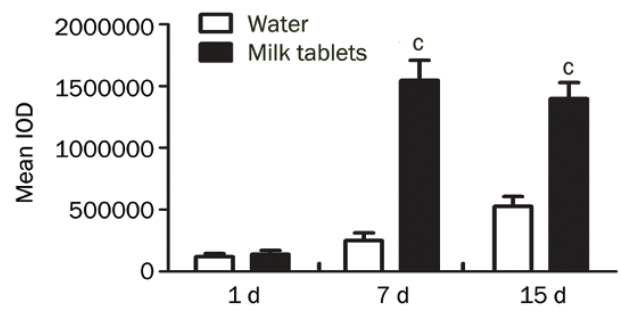

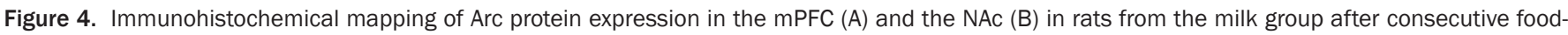

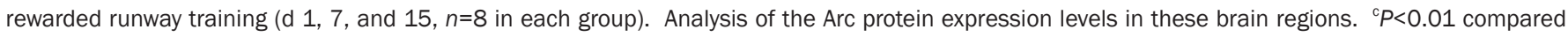
with saline with RW. Scale bars: $5 \mu \mathrm{m}$. 
A

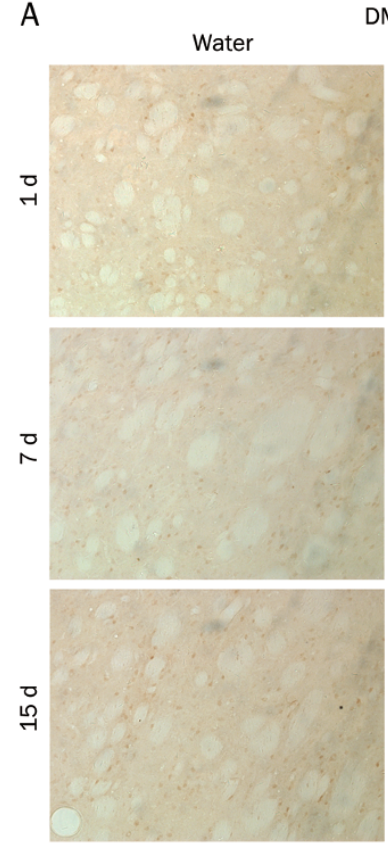

DMS
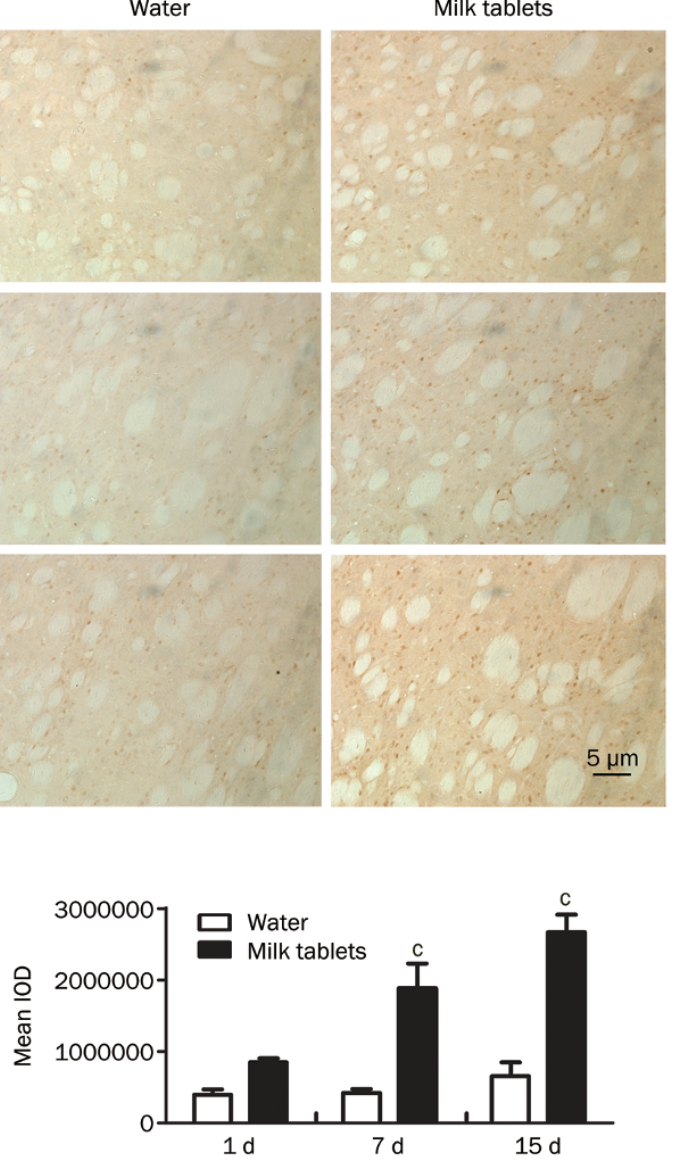

B
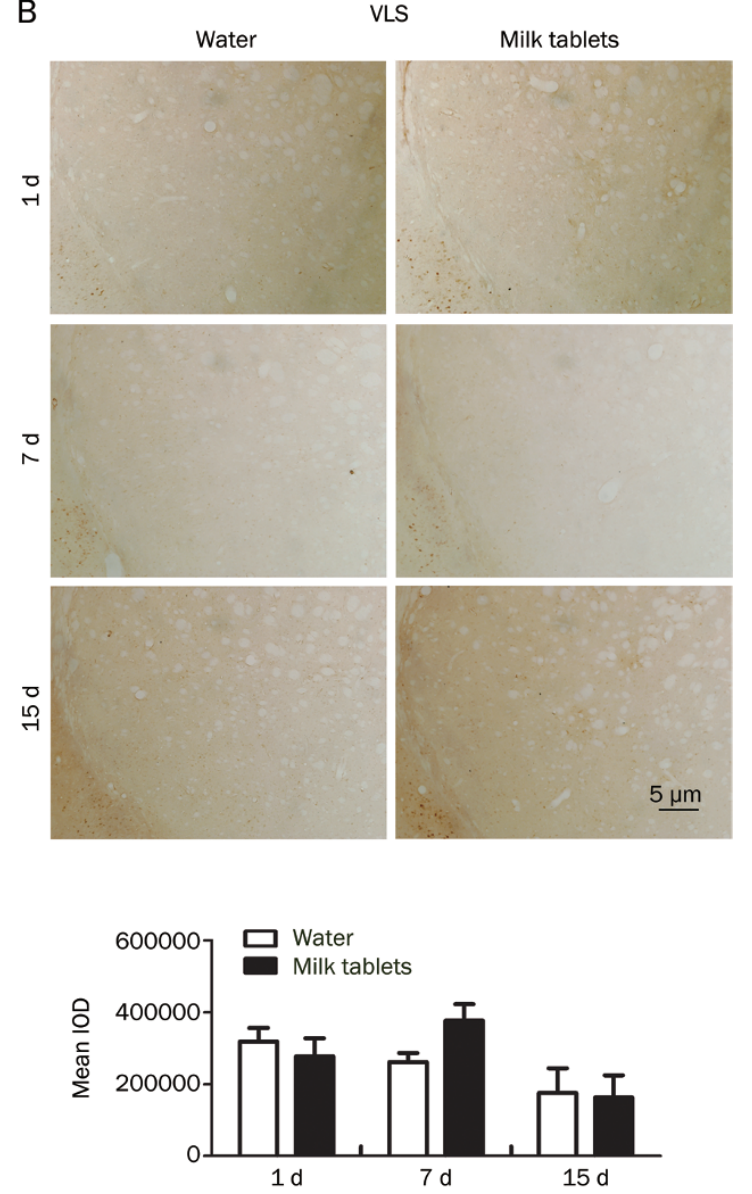

Figure 5. Immunohistochemical mapping of Arc protein expression in the DMS (A) and the VLS (B) in rats from the milk group after food-rewarded runway training ( $\mathrm{d} 1,7$, and $15, n=8$ in each group). Analysis of the Arc protein expression levels in these brain regions. ${ }^{\mathrm{C}} P<0.01$ compared with saline with RW. Scale bars: $5 \mu \mathrm{m}$.

the DMS on $\mathrm{d} 7$ and d 15, but this increase in Arc expression was not observed in the VLS, whereas for the rats trained with heroin, significant Arc protein expression was observed in the mPFC, the NAc and the DMS on d 1, 7, and 15, and in the VLS on $\mathrm{d} 1$ and $\mathrm{d} 7$ but not $\mathrm{d} 15$.

NMDA receptor and D1 dopamine receptor antagonists blocked both heroin-induced incentive-seeking behavior and Arc protein expression

It has been established that the NMDA receptor and the D1 dopamine receptor both play roles in the development and maintenance of drug motivational behaviors ${ }^{[33]}$ and that these two receptors are also involved in Arc expression ${ }^{[34-36]}$. To determine the relationship between heroin-induced runway behavior and Arc protein expression, we examined the effects of the NMDA receptor antagonist MK801 and the D1 dopamine receptor antagonist $\mathrm{SCH} 23390$ on heroin-induced runway behavior and Arc protein expression. Because the main parameter of the runway model to assess motivation is the running speed, which is influenced by locomotor activity, it is important to detect the run time without altering locomo- tor activity levels. To avoid changes in locomotor activity induced by MK801 or SCH23390, these two antagonists were administered (iv) when rats ran through the alley and broke the photobeam in the goal area, to ensure that the antagonists were administered at the same time as heroin was infused intravenously. The "run time" and the "latency" occurred before the presentation of the antagonists and hence were unaffected by the antagonists.

As shown in Figure 6A, runway training with heroin in combination with MK801 or SCH23390 increased run time compared with runway training with heroin alone. Analysis of the run time using ANOVA with the between-subjects factors of drugs and training days revealed a significant effect of drugs $\left(F_{(3,434)}=9.62, P<0.05\right)$ and training days $\left(F_{(14,434)}=4.35\right.$, $P<0.01)$, as well as a significant interaction between these two factors $\left(F_{(42,434)}=9.23, P<0.01\right)$. Analysis of the latency using ANOVA revealed a significant effect of drugs $\left(F_{(3,434)}=10.62\right.$, $P<0.05)$, no significant effect of training days $\left(F_{(14,434)}=1.46\right.$, $P>0.05)$ and a significant interaction between these two factors $\left(F_{(42,434)}=6.92, P<0.05\right)$. Post hoc Bonferroni differences within each time point are indicated in Figure 6A. These results indi- 
A
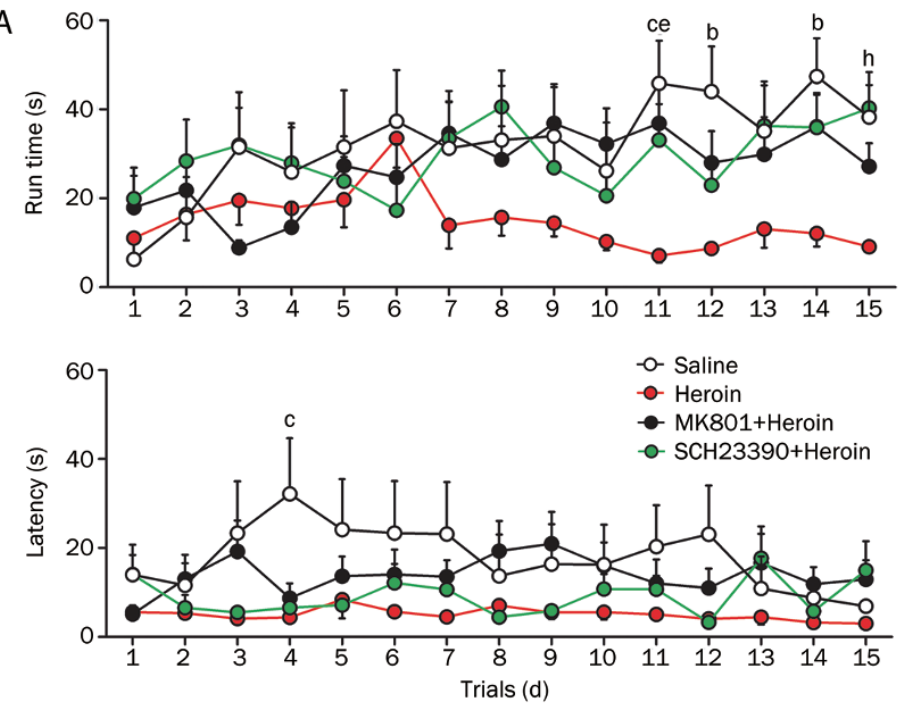

B
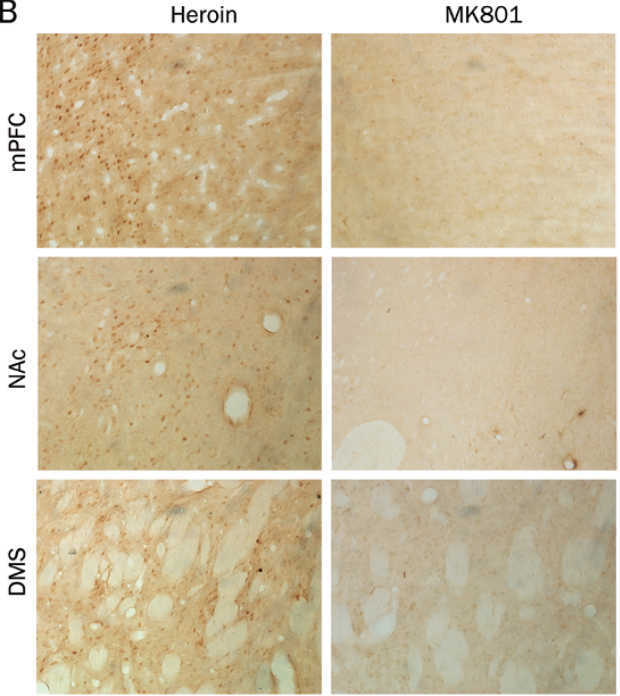

$\mathrm{SCH} 23390$

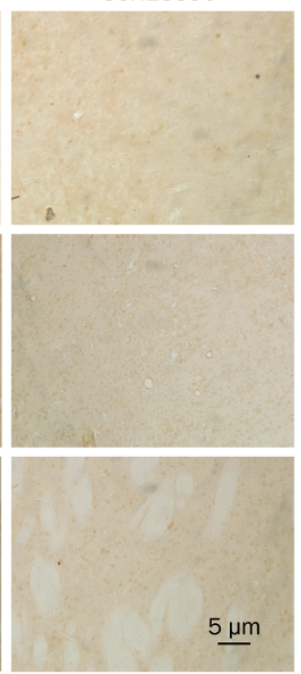

C
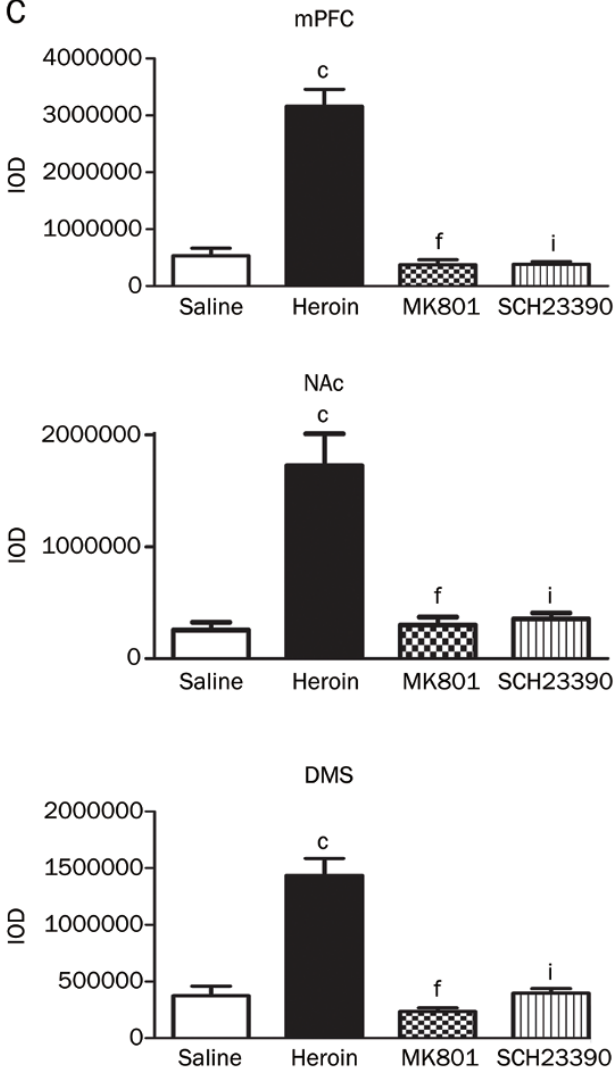

Figure 6. Effects of co-infusion of MK801 $(0.1 \mathrm{mg} / \mathrm{kg})$ or SCH $23390(0.03 \mathrm{mg} / \mathrm{kg})$ on the acquisition of runway behavior for intravenous heroin selfadministration over consecutive $15 \mathrm{~d}$. (A) Both MK801 $(n=10)$ and SCH23390 $(n=8)$ affected the rats' motivation for heroin compared with the heroin-reinforced group $(n=11)$. Saline group $(n=6)$. The figures show the effects on run time and latency. Data are shown as the mean $\pm S E M$. ${ }^{b} P<0.05,{ }^{c} P<0.01$ heroin group compared with saline group. ${ }^{e} P<0.05$ heroin group compared with MK801 group. ${ }^{\text {h}} P<0.05$ heroin group compared with $\mathrm{SCH} 23390$ group. Two-way ANOVA followed by Bonferroni post hoc tests. (B) Immunohistochemistry was used to map Arc protein expression in the $\mathrm{mPFC}$, the NAc and the DMS in the MK801 group and the $\mathrm{SCH} 23390$ group. Scale bars: $5 \mu \mathrm{m}$. (C) Analysis of the Arc protein expression levels in the $\mathrm{mPFC}$, the NAc and the DMS on d 15 of heroin reinforced runway training. ${ }^{\mathrm{C}} P<0.01$ compared with saline group. ${ }^{\mathrm{f}} P<0.01$ compared with heroin group. ' $P<0.01$ compared with heroin group.

cate that MK801 and SCH23390 both suppressed drug-seeking behavior motivated by heroin, suggesting that activation of both the NMDA receptor and the D1 dopamine receptor is essential for heroin-seeking behavior. We subsequently mapped and quantified Arc protein expression in the mPFC, the NAc and the DMS from rats that were used for detecting the effect of MK801 and SCH23390 on heroin-seeking behavior. As shown in Figure 6B, Arc protein expression in these regions was abolished, indicating that NMDA receptor and D1 dopamine receptors were also involved in regulating Arc protein expression. Together, these results suggest that Arc protein expression may be functionally correlated with drugseeking behavior motivated by heroin.

\section{Discussion}

In the present study, we trained rats to self-administer heroin or milk tablets using a classic runway drug self-administration paradigm and used immunohistochemical assays to detect the expression of Arc (a protein essential for the stabilization of LTP and the consolidation of memory) in various brain regions. We found that there were different temporal and spatial patterns of Arc expression in response to heroin and 
milk reinforcement learning. Although both heroin and milk reinforcement learning elicited changes in Arc expression in the $\mathrm{MPFC}$, the NAc and the DMS, only heroin reinforcement learning induced Arc expression within the VLS. In addition, although milk reinforcement learning also induced Arc protein expression in the MPFC, the NAc and the DMS, this upregulation was slower than that induced by heroin reinforcement learning. An increase in Arc expression was detected only after $\mathrm{d} 7$ of milk reinforcement learning, whereas an increase in Arc protein expression could be detected after $\mathrm{d}$ 1 of heroin reinforcement learning. Moreover, we found that increased Arc expression within the MPFC, the NAc and the VLS in response to runway training with heroin was induced by both the pharmacological effect of heroin and the runway training: heroin treatment without runway training resulted in increased Arc expression within these regions, but an additional increase in Arc expression was observed upon heroin treatment with runway training. We also concluded that the increase in Arc expression by runway training was region-specific because it failed to increase heroin-induced Arc expression in the DMS, suggesting that runway training could exert different effect on heroin-induced Arc expression in different brain regions.

The striatum has been shown to be critical for drugseeking and drug-taking. The NAc has an important role in primary drug reinforcement, while the striatum is critically involved in compulsive drug use after extensive drug taking experience ${ }^{[6,7]}$. There are two distinct learning processes occurring within the striatum: one in the medial striatum that is critical for acquisition and expression of goal-directed actions, and the other in the lateral striatum that mediates stimulusresponse habits ${ }^{[37,38]}$. Drug-seeking behavior is initially a goaldirected behavior in which a drug is sought and taken for its reinforcing or rewarding effects, but it ultimately becomes a cue-controlled behavior after extensive drug-taking experience $^{[6,7]}$. At a neural level, this transition from goal-directed action to cue-controlled drug seeking reflects a shift from ventral to dorsal striatal control over drug seeking ${ }^{[6,7]}$. Indeed, there are multiple sources of evidence indicating that the lateral striatum is critically involved in cue-controlled drugseeking behavior. For example, exposure of drug addicts to drug cues increases dopamine activity in the dorsal striatum, and this increase in dopamine activity is correlated with the intensity of the cue-induced craving ${ }^{[39,40]}$. Moreover, increased extracellular DA has been detected in the dorsolateral striatum (DLS) but not in the NAc, and infusion of a dopamine receptor antagonist into the DLS, but not into the NAc, diminished cuecontrolled cocaine seeking ${ }^{[41-44]}$. Direct evidence to support a role of the DLS in habitual drug seeking comes from a recent study that showed that functional inactivation of the DLS restored the sensitivity of cocaine seeking to devaluation of the drug outcome ${ }^{[45]}$.

In line with these studies, the present study demonstrates that heroin but not milk reinforcement learning induced increased Arc protein expression in the VLS, supporting the model that the VLS may be crucially involved in heroin- but not milk-seeking behaviors. Given the essential role of the VLS in cue-controlled drug seeking, our findings suggest that the VLS may play a critical role in compulsive drug seeking. The failure of milk reinforcement learning to induce Arc protein expression in the lateral striatum, as observed here, is consistent with previous demonstrations that the motivation for food depends on dopamine neurotransmission in the $\mathrm{NAc}^{[46-48]}$ and that blockade of dopamine transmission within the DLS does not alter instrumental responses to food ${ }^{[49]}$. The other novel finding of the present study is that an increase in Arc expression in the VLS was observed early (on d 1) in the heroin reinforcement learning, indicating that this region is activated early in the process of heroin reinforcement learning, which is not consistent with the notion that the lateral striatum becomes involved in drug seeking only after prolonged drug-taking experience, when drug use becomes habitual and stimulus-driven $^{[6,7]}$. This is in agreement with recent findings that the DLS dopamine already becomes involved in cocainetaking after very limited experience with the drug ${ }^{[48]}$ and that the midlateral striatum mediates instrumental responses at all stages of training ${ }^{[50]}$. These results extend the role of the lateral striatum in drug use beyond habitual aspects of cue-controlled drug seeking after prolonged drug taking experience.

The striatum is interconnected with the $\mathrm{mPFC}$ via glutamatergic fibers ${ }^{[51-53]}$ and receives dopaminergic afferents from the VTA and the substantia nigra pars compacta ${ }^{[54,55]}$. Dopamine transmission in this network plays a crucial role in instrumental behaviors ${ }^{[56-58]}$, but the NMDA-type glutamate receptor can exert an important effect on the functions of dopamine receptors ${ }^{[59]}$. In the present study, we found that blockade of NMDA receptors with MK801 or antagonism of dopamine D1 receptors with SCH23390 inhibited heroin reinforcement learning-induced Arc protein expression, indicating the involvement of a functional interaction of these two receptors in mediating Arc expression. We also found that treatment with either MK801 or SCH23390 blocked heroin reinforcement learning-induced drug-seeking behavior, suggesting a functional correlation between Arc expression and behavior. Given the important role of Arc in synaptic plasticity and in learning and memory, our results suggest that NMDA- and dopamine-receptor-dependent Arc expression may be involved in drug-seeking behavior.

Taken together, the findings of the present study provide molecular evidence demonstrating that the VLS is involved in drug- but not food-seeking behavior and reveal that the VLS is activated early in the process of heroin reinforcement learning, These results therefore extend the role of the VLS in drug use beyond the habitual aspects of cue-controlled drug seeking, after a prolonged drug taking experience.

\section{Acknowledgements}

This research was supported by grants from the National Basic Research Program, a grant from the Ministry of Science and Technology of China 2009CB522005 (Jing-gen LIU), by National Natural Science Foundation of China 81130087 (Jinggen LIU), 91232716 (Jing-gen LIU), and by the Foundation of 
Natural Science of Jiangshu Province SBK201241521 (Yu-hua WANG).

\section{Author contribution}

$\mathrm{Mu} \mathrm{LI}$ and Bin LU designed the research; Mu LI and Wenjie LIU performed the research; Mu LI and Yu-hua WANG analyzed the data; Mu LI wrote the paper; and Jing-gen LIU revised the paper.

\section{References}

1 Daw ND, Niv Y, Dayan P. Uncertainty-based competition between prefrontal and dorsolateral striatal systems for behavioral control. Nat Neurosci 1005; 8: 1704-11.

2 Samejima K, Doya K. Multiple representations of belief states and action values in corticobasal ganglia loops. Ann N Y Acad Sci 2007; 1104: 213-28.

3 Voorn P, Vanderschuren L, Groenewegen HJ, Robbins TW, Pennartz CM. Putting a spin on the dorsal-ventral divide of the striatum. Trends Neurosci 2004; 27: 468-74.

4 Miyachi S, Hikosaka O, Lu X. Differential activation of monkey striatal neurons in the early and late stages of procedural learning. Exp Brain Res 2002; 146: 122-6.

5 Yin $\mathrm{HH}$, Ostlund SB, Knowlton BJ, Balleine BW. The role of the dorsomedial striatum in instrumental conditioning. Eur J Neurosci 2005; 22: 513-23.

6 Yin $\mathrm{HH}$, Knowlton BJ, Balleine BW. Lesions of dorsolateral striatum preserve outcome expectancy but disrupt habit formation in instrumental learning. Eur J Neurosci 2004; 19: 181-9.

7 Everitt BJ, Robbins TW. Neural systems of reinforcement for drug addiction: from actions to habits to compulsion. Nat Neurosci 2005; 8: 1481-9.

8 Pierce RC, Vanderschuren $\sqcup$. Kicking the habit: the neural basis of ingrained behaviors in cocaine addiction. Neurosci Biobehav Rev 2010; 35: 212-9.

9 Fuchs RA, Branham RK, See RE. Different neural substrates mediate cocaine seeking after abstinence versus extinction training: a critical role for the dorsolateral caudate-putmen. J Nerurosci 2006; 26 : 3584-8.

10 See RE, Elliott JC, Feltenstein MW. The role of dorsal vs ventral striatal pathways in cocaine-seeking behavior after prolonged abstinence in rats. Psychopharmacology (Berl) 2007; 194: 321-31.

11 Cardinal RN, Parkinson JA, Lachenal G, Halkerston KM, Rudarakanchana N, Hall J, et al. Effects of selective excitotoxic lesions of the nucleus accumbens core, anterior cingulate cortex, and central nucleus of the amygdala on autoshaping performance in rats. Behav Neurosci 2002; 116: 553-67.

12 Wyvell CL, Berridge KC. Intra-accumbens amphetamine increases the conditioned incentive salience of sucrose reward: enhancement of reward "wanting" without enhanced "liking" or response reinforcement. J Neurosci 2000; 20: 8122-30.

13 Wise RA. Dopamine, learning and motivation. Nat Rev Neurosci 2004; 5: 483-94.

14 Balleine BW, Dickinson A. Goal-directed instrumental action: contingency and incentive learning and their cortical substrates. Neuropharmacology 1998; 37: 407-19.

15 Killcross S, Coutureau E. Coordination of actions and habits in the medial prefrontal cortex of rats. Cereb Cortex 2003; 13: 400-8.

16 Abraham WC, Mason SE, Demmer J, Williams JM, Richardson CL, Tate WP, et al. Correlations between immediate early gene induction and the persistence of Iong-term potentiation. Neuroscience 1993; 56:
717-27.

17 Worley PF, Bhat RV, Baraban JM, Erickson CA, McNaughton BL, Barnes CA. Thresholds for synaptic activation of transcription factors in hippocampus: correlation with long-term enhancement. J Neurosci 1993; 13: 4776-86.

18 Hess US, Lynch G, Gall CM. Regional patterns of c-fos mRNA expression in rat hippocampus following exploration of a novel environment versus performance of a well-learned discrimination. J Neurosci 1995; 15: 7796-809.

19 Vann SD, Brown MW, Erichsen JT, Aggleton JP. Fos imaging reveals differential patterns of hippocampal and parahippocampal subfield activation in rats in response to different spatial memory tests. J Neurosci 2000; 20: 2711-8.

20 Tzingounis AV, Nicoll RA. Arc/Arg3.1: linking gene expression to synaptic plasticity and memory. Neuron 2006; 52: 403-7.

21 Guzowski JF, Lyford GL, Stevenson GD, Houston FP, McGaugh $\mathrm{JL}$, Worley PF, et al. Inhibition of activity-dependent arc protein expression in the rat hippocampus impairs the maintenance of longterm potentiation and the consolidation of long-term memory. J Neurosci 2000; 20: 3993-4001.

22 Plath N, Ohana O, Dammermann B, Errington ML, Schmitz D, Gross C, et al. Arc/Arg3.1 is essential for the consolidation of synaptic plasticity and memories. Neuron 2006; 52: 437-44.

23 Dynes JL, Steward O. Dynamics of bidirectional transport of Arc mRNA in neuronal dendrites. J Comp Neurol 2007; 500: 433-47.

24 Wakonigg G, Sturm K, Saria A, Zernig G. Opioids, cocaine, and food change runtime distribution in a rat runway procedure. Psychopharmacology (Berl) 2003; 169: 52-9.

25 Geist TD, Ettenberg A. A simple method for studying intravenous drug reinforcement in a runaway. Pharmacol Biochem Behav 1990; 36: 703-6.

26 Lu B, Li M, Hou YY, Chen J, Chi ZQ, Liu JG. Initial experience of heroin use under a two-chained operant schedule influences drug-seeking behavior after one month of abstinence. Acta Pharmacol Sin 2010; 31: 387-92.

27 Fadda P, Robinson L, Fratta W, Pertwee RG, Riedel G. Scopolamine and MK801-induced working memory deficits in rats are not reversed by CBD-rich cannabis extracts. Behav Brain Res 2006; 168: 307-11.

28 Liu X, Jerniqen C, Gharib M, Booth S, Caqqiula AR, Sved AF. Effects of dopamine antagonists on drug cue-induced reinstatement of nicotineseeking behavior in rats. Behav Pharmacol 2010; 21: 153-60.

29 Sato SM, Wissman AM, McCollum AF, Wooley CS. Quantitative mapping of cocaine-induced $\triangle F$ osB expression in the striatum of male and female rats. PLoS One 2011; 6: e21783.

30 Li M, Hou YY, Lu B, Chen J, Chi ZQ, Liu JG. Expression pattern of neural synaptic plasticity marker-Arc in different brain regions induced by conditioned drug withdrawal from acute morphine-dependent rats. Acta Pharmacol Sin 2009; 30: 282-90.

31 Groenewegen HJ, Berendse HW, Wolters JG, Lohman AH. The anatomical relationship of the prefrontal cortex with the striatopallidal system, the thalamus and the amygdala: evidence for a parallel organization. Prog Brain Res 1990; 85: 95-116.

32 Joel D, Weiner I. The organization of the basal ganglia-thalamocortical circuits: open interconnected rather than closed segregated. Neuroscience 1994; 63: 363-79.

33 Pierce RC, Kalivas PW. A circuitry model of the expression of behavioral sensitization to amphetamine-like psychostimulants. Brain Res Brain Res Rev 1997; 25: 192-216.

34 Fumagalli F, Bedogni F, Frasca A, Di Pasquale L, Racagni G, Riva MA. Corticostriatal up-regulation of activity-regulated cytoskeletalassociated protein expression after repeated exposure to cocaine. 
Mol Pharmacol 2006; 70: 1726-34.

35 Bloomer WA, VanDongen HM, VanDongen AM. Arc/Arg3.1 translation is controlled by convergent $N$-methyl- $D$-aspartate and Gs-coupled receptor signaling pathways. J Biol Chem 2008; 283: 582-92.

36 Liu Y, Zhou QX, Hou YY, Lu B, Yu C, Chen J, et al. Actin polymerizationdependent increase in synaptic Arc/Arg3.1 expression in the amygdala is crucial for the expression of aversive memory associated with drug withdrawal. J Neurosci 2012; 32: 12005-17.

37 Packard MG, Knowlton BJ. Learning and memory functions of the basal ganglia. Annu Rev Neurosci 2002; 25: 563-93.

38 Yin $\mathrm{HH}$, Knowlton BJ. The role of the basal ganglia in habit formation. Nat Rev Neurosci 2006; 7: 464-76.

39 Volkow ND, Wang GJ, Telang F, Fowler JS, Logan J, Childress AR, et al. Cocaine cues and dopamine in dorsal striatum: mechanism of craving in cocaine addiction. J Neurosci 2006; 26: 6583-8.

40 Wong DF, Kuwabara H, Schretlen DJ, Bonson KR, Zhou Y, Nandi A, et al. Increased occupancy of dopamine receptors in human striatum during cue-elicited cocaine craving. Neuropsychopharmacology 2006; 31: 2716-27.

41 Ito R, Dalley JW, Howes SR, Robbins TW, Everitt BJ. Dissociation in conditioned dopamine release in the nucleus accumbens core and shell in response to cocaine cues and during cocaine-seeking behavior in rats. J Neurosci 2000; 20: 7489-95.

42 Ito R, Dalley JW, Robbins TW, Everitt BJ. Dopamine release in the dorsal striatum during cocaine-seeking under the control of a drugassociated cue. J Neurosci 2002; 22: 6247-53.

43 Vanderschuren LJ, Di Ciano P, Everitt BJ. Involvement of the dorsal striatum in cue-controlled cocaine seeking. J Neurosci 2005; 25 : 8665-70.

44 Belin D, Everitt BJ. Cocaine seeking habits depend upon dopaminedependent serial connectivity linking the ventral with the dorsal striatum. Neuron 2008; 57: 432-41.

45 Zapata A, Minney VL, Shippenberg TS. Shift from goal-directed to habitual cocaine seeking after prolonged experience in rats. J Neurosci 2010; 30: 15457-63.

46 Aberman JE, Ward SJ, Salamone JD. Effects of dopamine antagonists and accumbens dopamine depletions on time-constrained progressive-ratio performance. Pharmacol Biochem Behav 1998; 61: 341-8.

47 Zhang M, Balmadrid C, Kelley AE. Nucleus accumbens opioid, GABAergic, and dopaminergic modulation of palatable food motiva- tion: contrasting effects revealed by a progressive ratio study in the rat. Behav Neurosci 2003; 117: 202-11.

48 Baldo BA, Kelley AE. Discrete neurochemical coding of distinguishable motivational processes: insights from nucleus accumbens control of feeding. Psychopharmacology 2007; 191: 439-59.

49 Veeneman MM, Broekhoven MH, Damsteegt R, Vanderschuren LJ. Distinct contributions of dopamine in the dorsolateral striatum and nucleus accumbens shell to the reinforcing properties of cocaine. Neuropsychopharmacology 2012; 37: 487-98.

50 Jonkman S, Pelloux Y, Everitt BJ. Differential roles of the dorsolateral and midlateral striatum in punished cocaine seeking. J Neurosci 2012; 32: 4645-50.

51 Christie MJ, James LB, Beart PM. An excitant amino acid projection from the medial prefrontal cortex to the anterior part of nucleus accumbens in the rat. J Neurochem 1985; 45: 477-82.

52 Kita H, Kosaka T, Heizmann CW. Parvalbumin-immunoreactive neurons in the rat neostriatum: a light and electron microscopic study. Brain Res 1990; 536: 1-15.

53 Brog JS, Salyapongse A, Deutch AY, Zahm DS. The patterns of afferent innervation of the core and shell in the "accumbens" part of the rat ventral striatum: immunohistochemical detection of retrogradely transported fluoro-gold. J Comp Neurol 1993; 338: 255-78.

54 Lindvall O, Björklund A, Divac I. Organization of cattecholamine neurons projecting to the frontal cortex in the rat. Brain Res 1978; 142: 1-24.

55 Beckstead RM, Domesick VB, Nauta WJ. Efferent connections of the substantia nigra and ventral tegmental area in the rat. Brain Res 1979; 175: 191-217.

56 Sawaguichi T, Goldman-Rakic PS. D1 dopamine receptors in prefrontal cortex: involvement in working memory. Science 1991; 251: $947-50$.

57 Salamone JD. The involvement of nucleus accumbens dopamine in appetitive and aversive motivation. Behav Brain Res 1994; 61: 117-33.

58 Beninger RJ, Miller R. Dopamine D1-like receptors and reward-related incentive learning. Neurosci Biobehav Rev 1998; 22: 335-45.

59 Smith-Roe SL, Kelley AE. Coincident activation of NMDA and dopamine D1 receptors within the nucleus accumbens core is required for appetitive instrumental learning. J Neurosci 2000; 20: 7737-42. 